\title{
A three years retrospective study of life threatening complications following caesarean section
}

\author{
Aloke Kumar De, Sanjoy Kumar Bhattacharyya, Sohini Biswas, Nancy Gupta \\ Correspondence: Dr. Sanjoy Kumar Bhattacharyya, Assistant Professor, Department of \\ Obstetrics and Gynecology, RG Kar Medical College, Kolkata, India. \\ Email - sanjay.krbhattacharyya@gmail.com
}

Distributed under Attribution-NonCommercial - Share Alike 4.0 International (CC BY-NC-SA 4.0)

\begin{abstract}
Objectives: To study retrospectively the life threatening complications of cesarean section, morbidity and mortality statistics of those women, their mode of management and to assess the possibility of any preventive steps. Methods: A retrospective study is carried out to assess the morbidity and mortality following Cesarean section during the period from $1^{\text {st }}$ January 2015 to $31^{\text {st }}$ December 2018. Results: Fifty two women in these three years experienced serious complications following cesarean section. Postpartum hemorrhage $(32.67 \%)$ was the leading complications followed by rectus sheath hematoma and medical complications (15.38\% each). Surgical interventions like obstetric hysterectomy, step wise devascularisation were the commonly adopted procedures. A majority of those women required dialysis as well as ventilatory support. Ten women died after cesarean section mainly due to different medical crisis. Conclusion: This study highlights the fact that complications following cesarean section sometimes prove fatal and this may not be reckoned as a safe operation.
\end{abstract}

Keywords: Cesarean section, postpartum hemorrhage, rectus sheath hematoma.

Caesarean birth is a major surgery and like other surgical procedures, risks are involved inherently. The estimated risk of a woman dying after a cesarean birth is 0.53 in 1000 where the same death risk following a vaginal birth is 0.04 in $1000{ }^{1}$. Though previously cesarean section (CS) was associated with risk of complications, now a day, with the use of safe anesthesia, suturing techniques, antiseptics, asepsis, blood transfusion and antibiotics; CS has become an increasingly safe and common procedure. But this continued improvement in safety has led to CS being done on demand today with no medical indications though the mortality related to caesarean birth is still 3-4 times higher than vaginal birth.
The main reasons for increased mortality after CS are post-partum hemorrhage, complications of anesthesia, thromboembolism and postpartum infections ${ }^{2}$. On rare occasions some even need hysterectomy to save their lives. This study tries to analyze the fatal complications in cesarean sections stressing the fact that this operation is not safe even in expert hands and only to be done when indications are justified.

\section{Materials and methods}

This retrospective study was carried out in R G Kar Medical College, Kolkata, India during a period from $1^{\text {st }}$ January 2015 to $31^{\text {st }}$ December 2018, to find out the immediate and late life threatening complications those

Received: $24^{\text {th }}$ June 2019 . Accepted: $2^{\text {nd }}$ July 2019.

De AK, Bhattacharyya SK, Biswas S, Gupta N. A three years retrospective study of life threatening complications following caesarean section. The New Indian Journal of OBGYN. 2020; 6(2): 92-6. 
The New Indian Journal of OBGYN. 2020 (January-June); 6(2)

developed following C S.

All those women who needed relaparotomy following CS were included. This study also enrolls and analyses those cases, who needed dialysis, ventilatory support, ICCU admission or/and blood product transfusions of more than 5 units along with or apart from any major surgical intervention following a CS.

Postoperative minor complications those developed following C S, like superficial wound dehiscence, postpartum hemorrhage or small rectus sheath hematoma (RSH) which were managed conservatively, puerperal sepsis or minor anesthetic hazards were excluded from the study.

Data were collected from operation theatre register, maternal death register, particular case record sheets and from the register of high dependency units.

All those cases were enrolled and analyzed accordingly-

1.Demographic profile like age, obstetric profiles, referral status and time of development of complications.

2. Indications of CS

4. Types of management

5. Estimation of maternal deaths following CS and its relationship with primary surgery, if any.

6. To find out the possible steps for prevention of those deadly complications.

This study was cleared by the institutional ethics committee. Data were expressed in contingency tables with number and percentage.

\section{Results and observations}

A total 49628 deliveries were conducted in this hospital since last three years among which 16873 were

Table 1: Demographic profile $(\mathrm{N}=52)$

\begin{tabular}{lll}
\hline Categories & & No (\%) \\
\hline Age in years & $<20$ & $6(11.5 \%)$ \\
& $20-30$ & $32(61.5 \%)$ \\
& $>30$ & $14(26.9 \%)$ \\
\hline Parity & 0 & $19(36.5 \%)$ \\
& $1-3$ & $28(53.8 \%)$ \\
& $>3$ & $5(9.6 \%)$ \\
\hline Referral / Direct & Referral & $15(28.84 \%)$ \\
& Direct & $37(71.15 \%)$ \\
\hline CS complications & Immediate & $8(15.4 \%)$ \\
interval in hours & $<24$ & $29(55.76 \%)$ \\
& $24-48$ & $6(11.5)$ \\
& $48-72$ & $1(1.9 \%)$ \\
& $>72$ & $8(15.4 \%)$ \\
\hline
\end{tabular}

Table 2: Indications of primary LUCS

\begin{tabular}{lll}
\hline Indications & $\begin{array}{l}\text { Women } \\
\text { No }(\%)\end{array}$ & $\begin{array}{l}\text { Maternal Death } \\
(\mathbf{N = 1 0 )}\end{array}$ \\
\hline Post and repeat CS & $15(28.8 \%)$ & 1 \\
Fetal distress & $4(7.7 \%)$ & - \\
Preeclampsia and eclampsia & $11(21.1 \%)$ & 3 \\
Antepartum hemorrhage & $12(23.07 \%)$ & 2 \\
Composite indications & $6(11.5 \%)$ & 2 \\
Not known & $4(7.7 \%)$ & 2 \\
\hline
\end{tabular}

cesarean birth (34\%). We had 42 near miss women who suffered major complications, immediate or delayed,

Table 3: Types of complications following CS

\begin{tabular}{lll}
\hline Types of complications & $\begin{array}{l}\text { Women } \\
\text { No (\%) }\end{array}$ & $\begin{array}{l}\text { Maternal } \\
\text { Death (N=10) }\end{array}$ \\
\hline $\begin{array}{l}\text { Primary PPH needing } \\
\text { surgical intervention }\end{array}$ & $12(23.07 \%)$ & 3 \\
$\begin{array}{l}\text { Secondary PPH needing } \\
\text { surgical intervention }\end{array}$ & $5(9.6 \%)$ & - \\
$\begin{array}{l}\text { Rectus sheath hematoma } \\
\text { Bladder injury }\end{array}$ & $8(15.38 \%)$ & 1 \\
$\begin{array}{l}\text { Rupture uterus } \\
\text { Burst abdomen }\end{array}$ & $5(9.6 \%)$ & - \\
$\begin{array}{l}\text { Puerperal sepsis needing } \\
\text { surgical intervention }\end{array}$ & $6(11.53 \%)$ & - \\
$\begin{array}{l}\text { Medical complications } \\
\text { following CS }\end{array}$ & $6(11.53 \%)$ & 2 \\
\hline \begin{tabular}{l} 
Three \\
\hline
\end{tabular} & $8(15.38 \%)$ & 4 \\
\hline
\end{tabular}

Three women encountered multiple types of surgical complications; Two women had ruptured uterus; Two women had associated bladder injury.

after cesarean section. Ten women died following CS despite of all efforts.

Table 1 shows the demographic profile where majority of the women were in the age group of 20-30 (61.5\%) years, multiparous (53.8\%). Maximum women developed complications within first 24 hours following CS (55.76\%).

Table 2 shows the indications for which those women were posted for CS. Majority of women were either post or repeat CS and/or suffered from antepartum hemorrhage (28.8 and $23.07 \%$ respectively). Preeclampsia/eclampsia was the next major indication for CS (21.1\%). We could not find out the indications in few cases where the CS was performed elsewhere and the women following surgery were referred and admitted in this institution.

Table 3 demonstrates the types of complications aroused following the primary surgery. Postpartum hemorrhage (PPH) was the major type of morbidity here 
Table 4: Management procedures

\begin{tabular}{lll}
\hline Management procedures & Number of women & Maternal Death \\
\hline Total abdominal hysterectomy & 20 & 4 \\
Rectus sheath hematoma drainage & 8 & 1 \\
Scar excision & 4 & - \\
Step wise devascularisation ** & 12 & - \\
Bladder repair \# & 5 & - \\
Repair of burst abdomen & 6 & - \\
Dialysis & 19 & 3 \\
Ventilatory support & 16 & 7 \\
Transfusion of blood and blood products $>5$ units & 21 & 6 \\
\hline
\end{tabular}

More than one types of management were often required for single woman; ** 4 women underwent stepwise devascularisation followed by hysterectomy. Four women needed stepwise devascularisation along with scar excision. 2 women needed the same after hysterectomy; \# 2 women had associated rupture uterus.

$(32.67 \%)$ following which rectus sheath hematoma $(15.38 \%)$ and medical complications like disseminated intravascular coagulation, jaundice, renal failure or heart failure $(15.38 \%)$. Six women had developed puerperal sepsis and needed surgical intervention. Among 4, two women died despite all measures.

Table 4 shows the management procedures undertaken. A majority of women required either peripartum hysterectomy $(38.46 \%)$ or stepwise devascularisation $(23 \%)$ or both. Cesarean scar excision was another procedure adopted for 4 women who developed wound granuloma in their postoperative period and presented with postpartum hemorrhage. Drainage of rectus sheath hematoma and repair of burst abdomen were other procedures required (15.4\% and $11.53 \%)$. A fair percentage of women required ventilatory as well as dialysis support for recovery.

\section{Discussion}

There is a rising trend of CS worldwide since last three decades and aptly in 1985 the World Health Organization (WHO) stated: "There is no justification for any region to have CS rates higher than $10-15 \% "{ }^{3}$ But later this statement is questioned and WHO put another apparently contradicting sentence in 2015 with the headline "Every effort should be made to provide caesarean sections to women in need, rather than striving to achieve a specific rate" 4 .

However, as per the latest data [National Family Health Survey 2015-16 (NFHS-4) $]^{5}$, the cesarean rates at population level in India seem to be $17.2 \%$ and in $\mathrm{R} \mathrm{G}$ Kar medical College, the rate is $33.6 \%$. Being a tertiary care centre, we are overburdened with complicated as well as referral cases which could be the reason for the high incidence of cesarean section and subsequent complications. Considering the major complications only, those incidences are found almost double in occurrence in emergency surgery than in elective cesarean section candidates. This is not at all surprising as odd hours surgery always tends to be more complicated due to lack of expert senior surgeons, lack of adequate and proper assistance as well as delay in decision making.

Considering the overall complications, this is apparent that the real challenge still remains in the management of postpartum hemorrhage during or following cesarean section. In this study, we found surgeons encountered 12 cases of primary post partum hemorrhage and 5 fatal secondary postpartum hemorrhages following primary cesarean section where surgical interventions like step wise devascularisation, hysterectomy or both needed to save the patient. Some of them were presented with placenta praevia. Women with parity more than 4 and four or more $\mathrm{C}$ sections have 9 fold risk of placenta praevia ${ }^{6}$. Zaki et al reported a $60 \%$ rate of placenta accrete with three or more cesarean delivery ${ }^{7}$. We could not save three women among them as they developed irreversible organ damage following postpartum hemorrhage. Out of 5 secondary postpartum hemorrhages, scar excision and repair were done in 4 cases with secondary PPH. The scar was found infected with unhealthy granulation tissue eroding the uterine vessel. The scar was excised and the margins were sutured with delayed absorbable sutures after careful mobilization of bladder. All of them also underwent step wise devascularisation. Singh $\mathrm{K}$ et al described one similar 
case where they performed only uterine artery embolization with success ${ }^{8}$.

Bladder injury is not very uncommon during cesarean delivery especially when the bladder remains very adherent with the anterior uterine wall or abdominal cavity as seen in repeat $\mathrm{C} \mathrm{S}$ cases. Also it is more common when $\mathrm{C} \mathrm{S}$ was performed in second stage of labor or $\mathrm{C} \mathrm{S}$ done following failed vaginal birth after CS .According to the Royal College of Obstetricians and Gynecologists (RCOG), caesarean sections carry a risk of bladder injury $0.08-0.94 \%$ cases ${ }^{9}$.Out of five cases, in three, bladder was injured intraoperatively and appeared as a serious trouble for the surgeons to overcome. Among them, the two cases were repeat cesarean section and in another case the anterior low lying placenta eroded the posterior bladder wall. Other two cases bladder injury was associated with rupture uterus In all of them, the injury was identified intraoperatively and repaired by surgeons without any further postoperative morbidity.

Rectus sheath hematoma [RSH] is an uncommon but often misdiagnosed or lately diagnosed condition following $\mathrm{C} \mathrm{S}$. RSH can develop due to rupture of epigastric vessels or its branches or tear of the main muscles. Coughing, sneezing, direct trauma following $\mathrm{C}$ section in women with hypertension or having anticoagulant medications are more prone to develop RSH ${ }^{10}$. Among the 8 cases of RSH enrolled here, three of them were referral. All of them needed exploratory laparotomy due to their considerable size, extent as well as the condition of the patient. We could not save one of them as she had already developed DIC which can be a dreaded squeal of a large hematoma not evacuated urgently

Puerperal sepsis is a common complication after CS and in our experience, most of them resolved after conservative approach. However, 6 similar cases needed laparotomy as we had a suspicion of development of pus inside abdomen. Four of them even needed hysterectomy as the uterus appeared unhealthy during laparotomy.

Medical problems like renal failure, hepatic failure or DIC were complications as a sequel to the surgical stress on an already compromised state. Women with severe preeclampsia/eclampsia or with compromised liver function are often the candidates those developed acute morbidity following C S. As per our statistics, 19 women needed dialysis and 16 women needed ventilatory support as they developed severe complications following $\mathrm{C} \mathrm{S}$. Few women needed both. Apart from few surgical complications managed on table, most of the ailing women were treated in high dependency unit requiring almost all form of life supports.

In this study, we encountered 10 maternal deaths as a direct consequence of CS. Most of these deaths were the result of failure to overcome the medical crisis like acute renal failure, DIC, hepatorenal failure which developed subsequently and proved fatal. However, these conditions were partly related to the primary disease and aggravated by the superadded operative stress. Composite causes like eclampsia with renal failure or PPH with DIC were the reasons of three deaths.

Our study definitely has few limitations. We could not measure the true incidences of complications following $\mathrm{C}$ $\mathrm{S}$ here from these statistics. First of all, we included the referral cases here and thus, this total estimated data does not reflect the true percentage of $\mathrm{C} \mathrm{S}$ complications as the denominator remains undetermined. Secondly, minor postoperative complications like superficial wound dehiscence, small RSH managed conservatively or PPH controlled by medical management were not included and thus a huge number of complications were kept aside. As we had retrieved the data from the operative case record book and other registers retrospectively, there was no provision to collect those for estimation.

The way to primary prevention is perhaps to minimize the incidence of primary cesarean section with well justified indications. Women's' motivation for natural birth is urgently required. Secondary prevention is based on early diagnosis and timely referral of complicated cases. The final intervention succeeds only on adequate tertiary health care, good surgical expertise and availability of critical care facility. Repeated cesarean section surgery and to deal with its complications will be the greatest surgical challenge in the future.

\section{Conclusion}

Cesarean section is a major surgery and thus, complications following surgery are often serious. To minimize this, counseling for natural birth process should be encouraged. 
Conflict of interest: None. Disclaimer: Nil.

\section{References}

1. Schuitemaker N, Roosmalen J, Dekker G, van Dongen P, van Geijn H, Gravenhorst JB. Maternal mortality after cesarean section in The Netherlands. Acta Obstet Gynecol Scand. 1997; 76(4):332 - 4.

2. Esteves Pereira AP, Deneux Tharaux C, Nakamura Pereira M, Saucedo M, Bouvier-Colle MH, Leal Md C. Caesarean Delivery and Postpartum Maternal Mortality: A Population-Based Case Control Study in Brazil. PLOS ONE. 2016; 11(4): e0153396.

3. World Health Organization. Appropriate technology for birth. Lancet. 1985; 2 (8452): 436-7

4. World Health Organization. WHO Statement on Caesarean Section Rates. Geneva: World Health Organization; 2015 (WHO/ RHR/15.02).

5. International Institute for population sciences. National family health Survey 2015-16 (NHFS-4). Mumbai: International Institute for population sciences; 2017.

6. Gilliam M, Rosenberg D, Davis F. The likelihood of placenta accrete in greater number of cesarean delivaries and high parity. Obstet Gynecol. 2002; 99: 976-80.
7. Zaki Z, Bahar AM, Ali ME. Risk factor and morbidity in patients with placenta praevia accrete compared with placenta praevia nonacreta. Acta Obstet Gynaecol Scand. 1998;77; 391- 4.

8. Singh K, Bharati G, Kumari S, Tripathy N. Pseudo aneurysm of uterine artery and cesarean scar dehiscence causing secondary post-partum haemorrhage managed by uterine artery embolisation: a case report. Int J Reprod Contracept Obstet Gynecol. 2016; 5(8): 2895-8.

9. Christopher MT. Bladder Injury During Cesarean Delivery. Curr Womens Health Rev. 2013 May; 9(2): 70 - 6.

10. Upadhyaya I, Joshi NR. Post-caesarean Rectus Sheath Haematoma. Nepal Journal of Obstetrics and Gynaecology. 2016; 10(2): 60.

\footnotetext{
Aloke Kumar De ${ }^{1}$, Sanjoy Kumar Bhattacharyya ${ }^{2}$, Sohini Biswas ${ }^{3}$, Nancy Gupta ${ }^{4}$ ${ }^{1}$ Associate Professor; ${ }^{2}$ Assistant Professor; ${ }^{3,4}$ Postgraduate trainee, Department of Gynecology and Obstetrics, R G Kar Medical College, Kolkata, West Bengal, India
} 